\title{
Health and work: what physicians need to know
}

\author{
Authors: Karen Walker-Bone ${ }^{A}$ and Rosemary Hollick ${ }^{B}$
}

Employment, along with education, is central to the promotion of social mobility and the reduction of health inequalities. For the most part, however, physicians have limited exposure to occupational medicine during their training and rarely receive much in the way of formal training about occupational issues except those that fall commonly within their area of specialisation. Here, we illustrate why work and good employment can be so important for health and, therefore, why it should matter to all physicians. Given that under half of the UK population have access to occupational health services through their employer, physicians should be able to recognise any harm to health caused by work, so we describe the principles of eliciting a good occupational history. There is an important relationship between unemployment and poor health which will be discussed, illustrating the importance of being able to support people with long-term conditions and disabilities to remain in work for as long as they wish to do so. Patients expect to be able to seek advice from their physician about taking time off work because of ill health, planning a return to work after sickness absence and whether or not they need to change their work status because of their health condition. Therefore, we describe the fitnote: what it is for, how to complete one well and what core principles are needed in order to give patients good advice about working.

KEYWORDS: work and health, occupation, fitnote, work disability

DOI: 10.7861/clinmed.2020-0847

\section{Introduction}

As physicians, most of us have fulfilling jobs, which provide structure and meaning in our lives, status in our communities, money to pay our bills and rewards us intrinsically. The importance

Authors: ${ }^{\text {A }}$ professor of occupational rheumatology and director, MRC Versus Arthritis Centre for Musculoskeletal Health and Work, Southampton, UK, MRC Lifecourse Epidemiology Unit, University of Southampton, Southampton, UK and Southampton General Hospital, Southampton, UK; ${ }^{B}$ senior clinical lecturer and honorary consultant rheumatologist, School of Medicine, Aberdeen, UK, Aberdeen Centre for Arthritis and Musculoskeletal Health, Aberdeen, UK and MRC Versus Arthritis Centre for Musculoskeletal Health and Work, Aberdeen, UK and relevance of work to health and wellbeing extends across all of society. Work can facilitate social mobility, promote inclusivity and should be regarded as a basic human right: in fact, work is central to human existence. ${ }^{1}$ Its importance and relevance to health is most clearly highlighted among workless people, who have a higher prevalence of mental illness; worse poverty; considerably increased risk of self-harm; and a $20-30 \%$ greater risk of suicide. ${ }^{2,3}$ Worklessness translates into higher rates of mortality equating to an estimated 5-10 years' shorter life expectancy. ${ }^{4}$ Reliance on welfare benefits is stigmatising, can adversely impact physical and mental health and widens health inequalities. All physicians have a responsibility to consider the relationship between work and health for their patients in order to identify whether work is causing or contributing harm to health; support those with ill-health to remain in work or return to work if they so choose; and recommend sickness absence or changes in work status appropriately.

\section{Work as the cause of harm to health}

Industrial and then occupational medicine developed as a specialty in response to workplace hazards that caused harm to health. Asbestosis, silicosis, berylliosis, phossy jaw, mesothelioma, leptospirosis, infection with bloodborne viruses, occupational deafness, vibration white finger, chloracne and a wide range of other occupational diseases are recognised. ${ }^{5}$ In many cases, the underlying exposures are identified and have either been eliminated or strategies for their control have been mandated (protective equipment, vaccination or health surveillance) with statutory responsibility for these controls falling to employers, regulated by law. This might create the perception that workrelated disease has been eradicated. Unfortunately, the reality is different; according to data from the European Union, 2.02 million people die from work-related diseases (not accidents) every year and these diseases cost at least 145 billion euros annually. ${ }^{6}$

Although new workplace hazards will continue to be identified, the vast majority of the health conditions which are now work-related (caused or made worse by work) are not found only in the workplace (eg mental ill health, stress, asthma or musculoskeletal disorders). ${ }^{7-9}$ When the disease or health outcome is not unique to the workplace, it can be more difficult to recognise and to ascribe causation and indeed to apply control measures. While a detailed knowledge of all occupational diseases is outside the scope of most physicians, they should all be aware of the diseases within their specialty that might be work-related and should be competent to take a brief occupational history from all patients (Table 1). Moreover, physicians should be aware of the wide range of conditions which are 'prescribed diseases' (eg carpal tunnel syndrome, 
Table 1. Principles of taking an occupational history

\section{Scenario}

Patient presenting with new clinical problem

The clinical problem could be work-related ${ }^{a}$

Elicited suggestion of relevant exposure to the current clinical problem

Establishing relationship between work and the clinical problem

Establishing whether the exposure is relevant to the current main job

Could the exposure be from outside work?

If the clinical problem is 'work-related', how will the employee and employer likely respond? ${ }^{a}$

\section{Information required}

Is this patient currently working? Doing what? In what type of industry? What type of conditions?

Check possible work exposures to relevant chemicals, biological agents, physical strains or noise

How might the patient have been exposed? How often? Are relevant controls in place?

Temporality, dose-response, reversibility, strength of association and specificity

Many people work more than one job at the same time. Casual 'cash in hand' work may be more hazardous! Exposure may be from past work: take full chronological occupational history to be sure

Exposures outside work are not necessarily risk assessed or controlled

If 'work-related', management of the clinical problem is likely to rely on effective collaboration between doctor(s), employee and employer ${ }^{a}$

\section{Suitable questions}

What work do you do? Do you have a job? What is your job? What do you do for a living?

$>$ Is it full time or part time?

$>$ How long have you been doing this job?

$>$ In what year and month did you start?

$>$ How long is your working day?

> Do you do shifts and what is the shift rotation?

$>$ What is a typical working day for you?

> What tasks do you do (lifting / twisting / working with arms above shoulder height)?

$>$ What processes do you work with?

$>$ How often?

$>$ For how long each day?

$>$ What materials do you work with?

> Do you have or have you had occupational exposure to fumes, chemicals, dust, loud noises, vibration, radiation or other occupational hazards?

> Have you been told that any of these might make you ill, that is, are hazardous?

$>$ How might you be exposed to this hazard?

$>$ What is the extent of your exposure to these materials?

$>$ How is exposure controlled?

$>$ Is there local extractor ventilation?

$>$ Do you wear special protective clothing?

$>$ Do you have any special medical tests because of this work?

$>$ When in relation to the exposure do/did the symptoms start?

$>$ Are the symptoms notably worse when you are working for longer in higher risk areas?

$>$ Are you better at the weekend or on holidays?

$>$ Does anyone at work have the same symptoms or other health problems?

$>$ Could any other exposure explain the symptoms (eg smoking)?

$>$ Do you have a second (or third) job?

$>$ Have you done this type of work elsewhere in the past?

> Have you done any other kind of work?

$>$ What jobs have you had since you left school?

If employment gaps:

$>$ Prison?

$>$ Armed forces?

$>$ Worked overseas?

$>$ How do you spend your free time? What are your hobbies?

$>$ What DIY or housework do you do (ie exposure to birds, adhesives or fumes)?

$>$ Do any of these hobbies or activities bring you into contact with chemicals, impure chemicals or breakdown products?

$>$ What is the patient's attitude?

$>$ What might be the employer's attitude?

$>$ What resources and expertise may be available to provide further information or to assist rehabilitation?

\footnotetext{
a'Work-related' ie caused or made worse by work.
} 
mesothelioma or hand-arm vibration syndrome) meaning that no-fault compensation can be paid to people with evidence of the exposure(s) and of the disease and resulting disablement through the Industrial Injuries Disablement Benefit scheme. ${ }^{10}$

\section{Promoting work retention for patients with long-term health conditions}

Once a 'patient' enters a consulting room or is admitted to hospital, it is easy for their working status to be ignored or forgotten. Stroke is the same, from a medical perspective, whether it is occurring in a farmer or an accountant. However, the subsequent rehabilitation of that individual can be markedly different, depending upon a range of factors including an assessment of the functional requirements to be able to do their job. After an epileptic seizure, an office worker who can use public transport is relatively easily able to return to their usual work while a professional driver cannot work in that capacity for at least 12 months. ${ }^{11}$ There is plenty of evidence that, outside of occupational medicine, few doctors consider the work impacts of the diagnoses that they make and that patients feel that they do not get the support they need for work from their specialists, ${ }^{12,13}$

As the prevalence of comorbidities is increasing, and as governments make legislative changes to encourage people to remain in work to older ages, there is a growing number of people trying to work with at least one, and often two or more, chronic long-term diseases. Many of the common long-term conditions might not appear to impact ability to work directly (eg diabetes, obesity, osteoarthritis or hypertension). However, these conditions can restrict the ability to meet some physical work demands and also affect work ability by causing fatigue, burnout, coexistent mental ill health, impacting mobility, and decreasing self-efficacy and confidence. Additionally, attending hospital and primary care appointments, investigations, blood monitoring, repeat prescriptions etc all make working more challenging. Many patients with long-term conditions use their annual leave to attend their appointments, reducing time available for their recovery. It is important to consider whether each appointment is really necessary and whether things can be scheduled all in one visit or out of working hours to show patients that their work matters, can be good for their health and can promote their rehabilitation and recovery.

There are a range of national, regional and local services available to support workers with disabilities or long-term conditions to be able to remain in work. Physicians need not be the experts but should be aware of, and able to signpost to, services (Table 2).

\section{Employers: prevention and retention}

Employers have legal responsibility to protect the health and safety of their employees. Larger employers also need to provide access to occupational health services for their employees but, in many cases, these are purchased from commercial providers and

Table 2. Supporting work for people with health conditions (UK)

Type of service
UK government services:
Access to work service
(www.gov.uk/government/
publications/access-to-work-
factsheet/access-to-work-
factsheet-for-customers)
Work coaches

Occupational health services

\section{Occupational therapists}

\section{Vocational rehabilitation services}

Third sector services:

Citizens Advice

Macmillan Cancer Support

Versus Arthritis

(musculoskeletal disorders)

MIND (mental health)

Etc

\section{Nature or provision}

Provides grants or sustained funding for practical support to enable people with health conditions or disabilities to get a job, undertake training or an apprenticeship, or sustain a job.

Based in local Job Centre Plus settings; these employment support workers can provide support for those out of work to find suitable work.

Larger employers are required to have occupational health provision, but this can be in-house or contracted from providers who are now mostly in the private sector. Not all services are the same.

Allied health professionals trained specifically to assess functional capability holistically including paid and unpaid work.

Usually staffed by allied health professionals with dedicated skills in supporting return to work after ill health and/or sickness.

Services providing information, support and signposting to enable work for people with specific types of health conditions.

\section{How to access}

Application is through employer based on the needs of the employee.

First point of contact for benefit claimants.

Employee and employer can request occupational health input where available. Some employers will contract on a 'once only' basis for a specific employee.

Patchily provided through NHS; may be available through primary care or secondary care services. Often based within one specialty (eg neurology or rheumatology).

Mostly provided commercially and paid for by employer or insurance company where individual or employer has funded cover.

Usually funded through charity and available for free. 
employers pay for a minimal level of service which often amounts to sickness absence management and/or telephone-based employee assistance programmes. It is important to be aware that an estimated $45 \%$ of the UK population do not have any occupational health support if they work in small and mediumsized enterprises. More enlightened employers do, however, invest in the health of their workforce through, for example, wellbeing programmes, campaigns around healthy eating, smoking cessation and/or promotion of physical activity. There are moral and ethical reasons for employers to do so, but there is also a financial one. There is considerable evidence that investment in the health and wellbeing of employees pays employers back considerably: reduced staff turnover (with its attendant costs); reduced working days lost to sickness absence and enhanced productivity (estimates range from $£ 3$ back for every $£ 1$ investment through to $£ 10-£ 20$ for each $£ 1$ investment). Despite these strong arguments for investment, there are unfortunately still a large number of employers offering poor-quality jobs at minimum wage, with zero-hour contracts that offer employees no paid sickness absence or leave.

\section{Fitnotes, sick leave and permanent work disability}

Sick leave is a strong predictor of permanent work disability. ${ }^{14}$ It has been shown that people off sick for more than 6 months with a musculoskeletal disorder only have a $50 \%$ chance of ever returning to work and that after 2 years' sickness, the proportion who return is virtually negligible. The reasons for this are complex: confidence and skills become eroded, working relationships break down, the job role is filled, the individual becomes accustomed to filling their time outside of work and may become embedded within the state benefit system so that they are 'trapped', afraid to try and go back to work in case they find themselves without any income if the return fails.

As a result, the UK 'sick note' was re-invented as the 'fitnote' in 2010 (Fig 1). The aim was to prevent unnecessary sick leave by encouraging doctors to give some thought before prescribing or extending sick leave ${ }^{1}$. Doctors are encouraged to provide additional advice to the employer about what aspects of their work the patient could still do. For example, a security officer with a recent exacerbation of chronic obstructive pulmonary disease might not be fit to do the more physical aspects of their role but might be able to watch the security monitors if on shift with a colleague who could provide support. Unfortunately, recent data suggest that as few as $10 \%$ of all fitnotes offer any such advice, so that they are failing to deliver their intended outcome. ${ }^{15}$ While the majority of fitnotes are written in primary care, hospital doctors are required to provide them when it will prevent an appointment in primary care. ${ }^{16}$ Some key frequently asked questions about how to write a fitnote are shown in Table 3.

In some cases, an individual's health, physical and mental capacity are no longer compatible with their job requirements. According to the latest available data from the Organisation for Economic Co-operation and Development (OECD), the UK is the country with the highest rate per capita of new claims for work disability. ${ }^{17}$ Patients finding their work demands exceeded by their capacity will seek advice about stopping work. Physicians may be unaware that only around $45 \%$ of UK workers have access to any occupational health $(\mathrm{OH})$ services and around $15 \%$ can access an $\mathrm{OH}$ physician through their employer. ${ }^{19}$ Therefore, it is often their

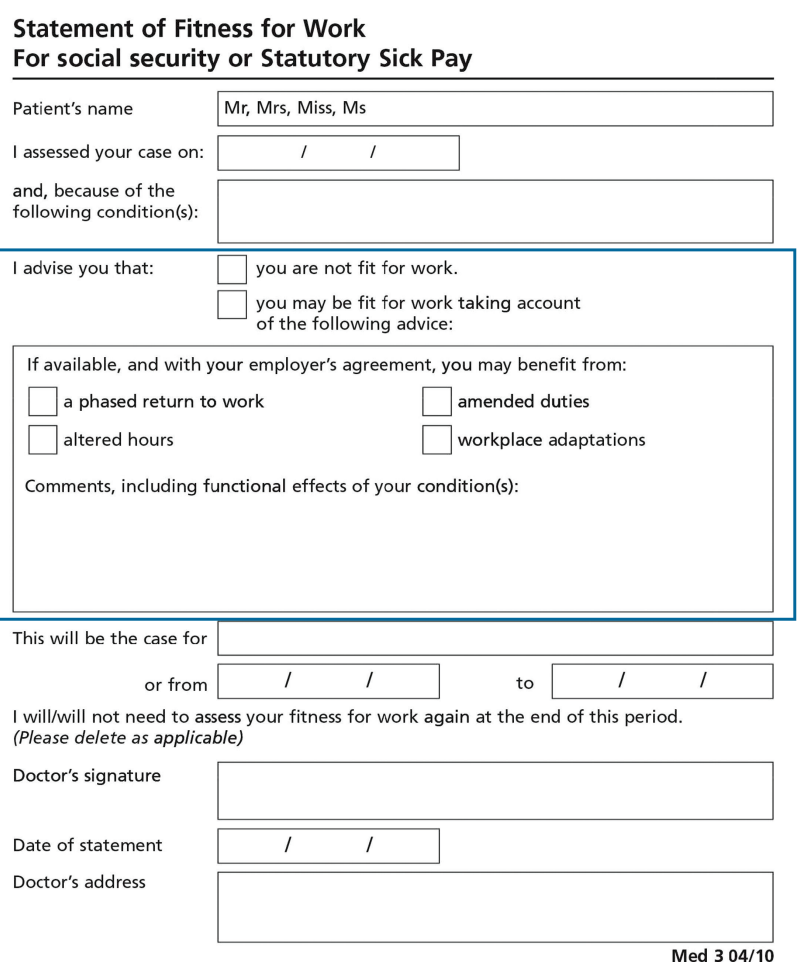

Fig 1. A sample fitnote showing the recommendations section for doctors to provide advice to their employee (blue box).

physician alongside their general practitioner who are best placed to advise about work capability. As a rheumatologist, I look back on how often my advice was to give up on their work, thinking that I was offering support and advocacy. I now know better: this decision is complex and, in general, people's health is worse if they stop work than if they carry on. ${ }^{19}$ Where possible, work should be adjusted to accommodate the individual's needs while retaining them at work. This principle is enshrined in the UK Equality Act 2010, in which 'disability' is a protected characteristic but many of our patients do not perceive themselves to be 'disabled'. Working as little as 4 hours/week can be valuable to a person's health and wellbeing. Not all jobs are good, nor are all employers willing to make the necessary accommodations, and this is what hampers healthcare providers from ultimately having control over work disability but, in general, physicians should emphasise the benefits of work and offer support to remain in good work.

\section{Conclusion}

Work and health are inextricably linked. The Academy of Medical Royal Colleges committed to a consensus statement for action around health and work in 2019. ${ }^{20}$ All physicians should be able to identify work-related disease and offer support and advice to enable work participation for patients who wish to work.

\section{Key points}

$>$ Work gives value and purpose to lives and good work is good for health and wellbeing. 
Table 3. Frequently asked questions about the fitnote

\section{Question}

Does my patient need a fitnote if they are only likely to be off for a week?

Who can write a fitnote?

When should hospital doctors write fitnotes?

What should I discuss with the patient?

Does the fitnote have legal implications?

How long should I give a fitnote for?

What does the fitnote have to do with benefits?

Can I say that my patient is NOT fit for work?

How do I know what advice to give about what they may be fit for?

What are the most common recommendations given to enable people with health conditions to stay at work?

What should my patient do with their fitnote?

\section{Answer}

No. Patients can self-certify for the first 7 calendar days of any period of sick leave.

Any doctor. The duty to provide a fitnote rests with the doctor who, at the time, has clinical responsibility for the patient. Some allied health professionals (AHP) can write an AHP health and work report which can be used with employers but does not give entitlement to benefit payments.

When discharging a patient from hospital and recommending sick leave.

In outpatient clinics if sick leave is needed.

To prevent the patient attending a general practitioner appointment only for a fitnote.

Their current health condition and what aspects of work it is affecting. Consider the following:

$>$ stamina eg better in the morning or the afternoon

$>$ mobility eg walking, bending and stooping

$>$ agility eg dexterity, posture and coordination

$>$ insight/stability eg mental state and mood

$>$ treatment eg side effects and duration

$>$ intellectual eg cognitive abilities

$>$ sensory eg hearing, vision and touch

$>$ the duration of their health condition and any likely fluctuation.

Regarding their current job: what are the hours worked, nature of work, type of industry, selfemployed or employed, have they had sickness absence already in this year?

Does their employer monitor sickness absence and does it have disciplinary procedures for exceeding days of sick leave?

Are there any aspects of their job that they feel they could still do with some adjustment (if the employer made it possible)?

Which aspects of their work are aggravating their health condition (if any)?

No, it is only a statement of your advice about whether or not they may be fit to work. Employees and employers can ignore your advice. Employers are not bound to follow your advice. However, they should always perform a risk assessment before bringing anyone in receipt of a fitnote into their workplace and doing so is at their own liability.

As short a time as possible. The maximum the fitnote can be written during the first 6 months is 3 months but think in terms of days or a small number of weeks. Remember that prolonged sick leave significantly reduces the ability to ever return to work.

The patient can use your fitnote as evidence for sick pay and benefit purposes

Yes. Always consider if your patient could do work of some kind before advising that they are not fit for any work. Remember the long-term health risks of worklessness when advising your patient that they are not fit for work.

Ask the patient about their job and all its requirements. Can they do any aspects of their own role? If not, are there other roles in that workplace/company that they think they might be able to undertake if the employer was willing on a temporary basis?

Reduction or change of working hours (later start times, earlier finish times).

Rotation of tasks with fellow employees.

Temporary reassignment to sedentary work.

Provision of car parking space nearer to the workplace.

Provision of equipment (eg light-weight laptop).

Temporary home-working.

Many adjustments are cheap and are based around employers being flexible with the employee.

They should take it to their employer and use it as a basis for a discussion about possible accommodation of their needs in the workplace. Your advice is not binding on the employer and they can choose to seek their own advice. 
Table 3. Frequently asked questions about the fitnote (Continued)

\section{Question}

If I give the advice and the employer cannot make these accommodations, what will happen?

Don't people need to be $100 \%$ fit to be able to work?

\section{Answer}

If the employer is unable to accommodate your advice, then they may treat it as a statement that the patient is not fit for work. You do not need to write another fitnote.

Absolutely not. We must bust this myth! Work can be part of rehabilitation from many health conditions (eg in a phased return to work).
> Worklessness is associated with poorer physical and mental health, poverty, self-harm and suicide.

> Prolonged sickness absence increases the risk of permanent work disability.

> Physicians need to enquire about their patients' work and feel confident taking a relevant occupational history, detecting harm to health from work and enabling work participation despite ill-health where possible.

\section{References}

1 Black C. Working for a healthier tomorrow. London: The Stationery Office, 2008. https://assets.publishing.service.gov.uk/government/ uploads/system/uploads/attachment_data/file/209782/hwwbworking-for-a-healthier-tomorrow.pdf

2 O'Shea B. Self-harm and unemployment. Hosp Med 2000;61: 495-8.

3 Nordt C, Warnke I, Seifrtitz E, Kawohl W. Modelling suicide and unemployment: a longitudinal analysis covering 63 countries, 2000-11. Lancet Psych 2015;2:239-45.

4 Moser KA, Fox AJ, Jones DR. Unemployment and mortality in the OPCS Longitudinal Study. Lancet 1984;2:1324-9.

5 Baxter PJ, Aw T-C, Cockroft A, Durrington P, Harrington JM (eds). Hunter's diseases of occupations, 10th edn. CRC Press, 2010.

6 International Labour Organization. The prevention of occupational diseases. Switzerland: International Labour Organization, 2013. www.ilo.org/wcmsp5/groups/public/—ed_protect/_protrav/— safework/documents/publication/wcms_208226.pdf [Accessed 01 October 2020]

7 Kumagai S. Two offset printing workers with cholangiocarcinoma. J Occup Health 2014;56:164-8.

8 De Matteis S, Heederik D, Burdorf A et al. Current and new challenges in occupational lung diseases. Eur Respir Rev 2017:26:170080.

9 All Party Parliamentary Group on Occupational Safety and Health. Occupational medical workforce crisis: The need for action to keep the UK workforce healthy. All Party Parliamentary Group on Occupational Safety and Health, 2016.

10 Department for Work and Pensions. Industrial Injuries Disablement Benefits: technical guidance. GOV.UK, 2019. www.gov.uk/ government/publications/industrial-injuries-disablement-benefitstechnical-guidance/industrial-injuries-disablement-benefits-technical- guidance\#appendix-1-list-of-diseases-covered-by-industrial-injuriesdisablement-benefit [Accessed 01 October 2020].

11 GOV.UK. Epilepsy and driving. GOV.UK. www.gov.uk/epilepsy-anddriving [Accessed 01 October 2020].

12 British Society of Rehabilitation Medicine. Vocational rehabilitation - the way forward: report of a working party. London: British Society of Rehabilitation Medicine; 2000.

13 Walker-Bone K, Black C. The importance of work participation as an outcome in Rheumatology. Rheumatology (Oxford) 2016:55:1345-7.

14 Winter CR. Using work, health and sick leave to predict work disability. International Social Security Review 2007:46:41-50.

15 NHS Digital. Fitnotes issues by GP practices England, March 2020. NHS, 2020. https://digital.nhs.uk/data-and-information/publications/statistical/fit-notes-issued-by-gp-practices/march-2020 [Accessed 01 October 2020].

16 Department for Work and Pensions. Statement of fitness for work: a guide for hospital doctors. GOV.UK, 2016. www.gov.uk/government/ publications/fit-note-guidance-for-hospital-doctors [Accessed 01 October 2020].

17 Organisation for Economic Co-operation and Development. Mental Health and Work: United Kingdom. Paris: OECD, 2014. https://read. oecd-ilibrary.org/employment/mental-health-and-work-unitedkingdom_9789264204997-en\#page44 [Accessed 01 October 2020].

18 Howlett E. Majority of UK workers don't have access to occupational health. People Management, 2019. www.peoplemanagement.co.uk/news/articles/uk-workers-do-not-have-accessoccupational-health [Accessed 01 October 2020].

19 Waddell G, Burton K. Is work good for your health and wellbeing? An independent review. Department for Work and Pensions, 2006.

20 Academy of Medical Royal Colleges. 2019 Healthcare Professionals' Consensus Statement for Action Statement for Health and Work. AoMRC, 2019. www.aomrc.org.uk/wp-content/ uploads/2019/04/Health-Work_Consensus_Statement_090419. pdf [Accessed 01 October 2020].

Address for correspondence: Prof Karen Walker-Bone, Southampton General Hospital, Southampton S016 6YD, UK. Email: kwb@mrc.soton.ac.uk 